\title{
Mechanistic aspects for the oxidation of sunset yellow dye by chloramine-T in presence of perchloric acid and in sodium hydroxide medium catalyzed by Os(VIII): A spectrophotometric kinetic approach
}

\author{
K.N. Vinod ${ }^{a}$, Puttaswamy ${ }^{\mathrm{a}, *}$, K.N. Ninge Gowda ${ }^{\mathrm{b}}$ \\ ${ }^{a}$ Department of Post-Graduate Studies in Chemistry, Central College Campus, Bangalore University, Bangalore 560 001, India \\ ${ }^{\mathrm{b}}$ Department of Apparel Technology and Management, Central College Campus, Bangalore University, Bangalore 560 001, India
}

\section{A R T I C L E I N F O}

\section{Article history:}

Received 13 June 2008

Received in revised form 4 September 2008

Accepted 16 September 2008

Available online 24 September 2008

\section{Keywords:}

Oxidation-kinetics

Sunset yellow

Chloramine-T

Os(VIII) catalysis

\begin{abstract}
A B S T R A C T
The kinetics of oxidation of sunset yellow (SY) by sodium- $N$-chloro- $p$-toluenesulfonamide or chloramine$\mathrm{T}$ (CAT) was studied spectrophotometrically in $\mathrm{HClO}_{4}$ and $\mathrm{NaOH}$ media with $\mathrm{Os}(\mathrm{VIII})$ as a catalyst in the latter medium at $298 \mathrm{~K}$ and $303 \mathrm{~K}$, respectively. In acid medium, the experimental rate law is - $\mathrm{d}$ [CAT]/ $\mathrm{d} t=k[\mathrm{CAT}]_{0}[\mathrm{SY}]_{0}\left[\mathrm{HClO}_{4}\right]^{-0.46}$. Alkali accelerates the rate of reaction and the rate law takes the form $-\mathrm{d}[\mathrm{CAT}] / \mathrm{d} t=k[\mathrm{CAT}]_{0}[\mathrm{SY}]_{0}[\mathrm{NaOH}]^{0.23}\left[\mathrm{OsO}_{4}\right]^{0.84}$. The solvent isotope effect was studied using $\mathrm{D}_{2} \mathrm{O}$. Benzenesulfonic acid and 1,2-naphthoquinone-6-sulfonic acid were characterized as the oxidation products of SY. Under identical set of experimental conditions in alkaline medium, Os(VIII) catalyzed reaction is about seven-fold faster than the uncatalyzed reaction. Activation parameters for the overall reaction and also with respect to catalyst have been evaluated. The observed results have been explained by plausible mechanisms and the related rate laws have been deduced.
\end{abstract}

(c) 2008 Elsevier B.V. All rights reserved.

\section{Introduction}

Sodium- $N$-chloro-4-methyl benzenesulfonamide, $\quad p-\mathrm{CH}_{3}-$ $\mathrm{C}_{6} \mathrm{H}_{4} \mathrm{SO}_{2} \mathrm{NClNa} \cdot 3 \mathrm{H}_{2} \mathrm{O}$, generally known as chloramine-T (CAT) is a very important member of organic $N$-halogenoamines [1-2]. Although the mechanistic aspects of many of its reactions have been well documented [2-8], a very little information is available in the literature on the oxidation kinetics of organic dyes with this reagent [9-10]. Sunset yellow, a pyrazolone dye (SY, disodium-2hydroxy-1(4-sulfonatophenylazo) naphthalene-6-sulfonate), is largely used in coloring food, cosmetics and medications [11]. Recently, the kinetics and mechanism of oxidative decolourisation of SY by peroxydisulphate has been reported by Gemeay et al. [12]. There seems to be no other reports in the literature on the oxidation of SY from the view point of its kinetic and mechanistic aspects.

The mechanism of catalysis is quite complex due to the formation of different complex intermediates, free radicals and differing oxidation states [13-16] of Os(VIII). Although many complexes of Os(VIII) with various organic and inorganic substances have been reported, the literature survey reveals that only sporadic references are available on the kinetic and mechanistic aspects of oxidation of organic dyes in general and azo dyes in particular involving Os(VIII) catalysis.

\footnotetext{
* Corresponding author. Tel.: +91 80 22961340; fax: +91 8022961335.

E-mail address: pswamy_chem@yahoo.com (Puttaswamy).
}

Our preliminary kinetic experiments revealed that the oxidation of SY by CAT in acid medium is facile but in alkaline medium the reaction is very sluggish to be measured. However, the use of micro quantity of Os(VIII) catalyst in alkaline medium brings about rapid oxidation. Hence, Os(VIII) was chosen as a catalyst for the oxidation of SY by CAT in alkaline medium for the detailed kinetic investigations. In view of this, we have taken up a systematic kinetic study of the oxidation of SY by CAT in presence of $\mathrm{HClO}_{4}$ as well as in $\mathrm{NaOH}$ medium with Os(VIII) as a catalyst in order to understand the mechanistic aspects of these redox systems.

\section{Experimental}

\subsection{Materials}

Chloramine-T (E-Merck) was purified by the method of Morris et al. [17]. An aqueous solution of the compound was standardized by the iodometric procedure and preserved in brown bottles to prevent its photochemical deterioration. Sunset yellow (Merck) was used without further purification. Aqueous solutions of desired strength were freshly prepared prior to use. A solution of Os (VIII), prepared in $0.5 \mathrm{~mol} \mathrm{dm}{ }^{-3} \mathrm{NaOH}$, was used as the catalyst. Allowance was made for the amount of alkali present in the catalyst solution, while preparing reaction mixtures for kinetic runs in alkaline medium. The rate of reaction was not affected when the reaction was studied at $0.20 \mathrm{~mol} \mathrm{dm}^{-3} \mathrm{NaClO}_{4}$ solution. Hence, no attempt was made to keep the ionic strength of the system 
constant for kinetic runs. Solvent isotope studies were made with $\mathrm{D}_{2} \mathrm{O}$ (99.2\%) supplied by the Bhabha Atomic Research Center, Mumbai, India. All other compounds employed were of accepted grades of purity. Double distilled water was used through out these kinetic reactions.

\subsection{Kinetic measurements}

Detailed kinetic runs were performed under pseudo-first-order conditions of [oxidant $]_{0} \gg$ [substrate $]_{0}$ at $298 \mathrm{~K}$ in presence of acid medium and $303 \mathrm{~K}$ in alkaline medium. The kinetic procedure followed is similar to that reported earlier [10]. Absorbance measurements were made at $483 \mathrm{~nm}$ ( $\lambda_{\max }$ of the dye) for more than two half-lives. The absorbance readings at $t=0$ and $t=t$ are $D_{0}$ and $D_{t}$. Plots of $\log D_{0} / D_{t}$ versus time were made to evaluate the pseudofirst-order rate constants $\left(k^{\prime} \mathrm{s}^{-1}\right)$, which were found to be reproducible to an accuracy of $\pm 4 \%$. Regression coefficient $(r)$ of the experimental data was carried out on an $f_{X}-100 \mathrm{~W}$ scientific calculator.

\section{Results and discussion}

\subsection{Stoichiometry and product analysis}

Reaction mixtures containing varying ratios of CAT to SY in presence of $1.0 \times 10^{-4} \mathrm{~mol} \mathrm{dm}^{-3} \mathrm{HClO}_{4}$ or $1.0 \times 10^{-3} \mathrm{~mol} \mathrm{dm}^{-3}$ $\mathrm{NaOH}$ (and $2.0 \times 10^{-5} \mathrm{~mol} \mathrm{dm}^{-3} \mathrm{Os}$ (VIII) in alkaline medium) were equilibrated at $298 \mathrm{~K}$ in acidic and $303 \mathrm{~K}$ in alkaline media, respectively for $24 \mathrm{~h}$. Determination of unreacted CAT by iodometry showed that one mole of SY consumed one mole of CAT in both the media. The observed stoichiometry can be represented by Eq. (1).
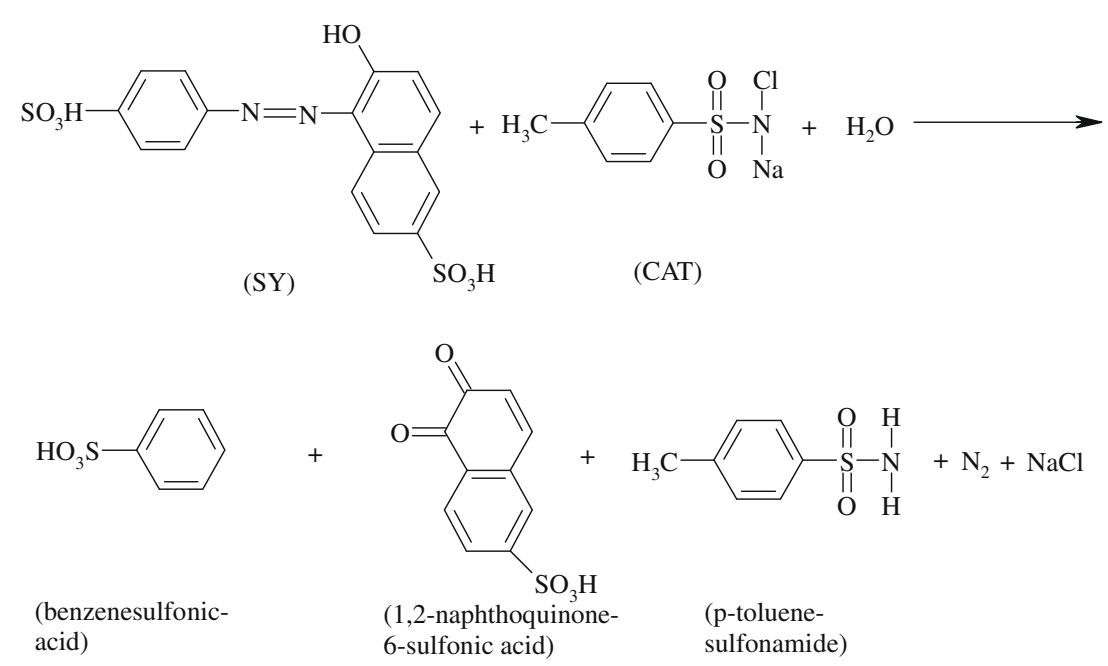

The reaction mixture in the stoichiometric ratio, under stirred condition, was allowed to progress in acid and alkaline media separately for $24 \mathrm{~h}$ at room temperature. After completion of the reaction, products were neutralized with $\mathrm{NaOH} / \mathrm{HCl}$ and extracted with ether. The organic products were subjected to spot tests and chromatographic analysis (TLC technique), which revealed the formation of oxidation products, namely benzenesulfonic acid and 1,2-naphthoquinone-6-sulfonic acid. These products were separated by column chromatography and were confirmed by GC-MS analysis. The mass spectra showed a molecular ion peak at $158 \mathrm{amu}$ and $238 \mathrm{amu}$ clearly confirming benzenesulfonic acid and 1,2-naphthoquinone-6-sulfonic acid, respectively.
$p$-Toluenesulfonamide in the reaction mixture was extracted with ethyl acetate and was detected by paper chromatography [9] using benzyl alcohol saturated with water as solvent, with $0.5 \%$ vanillin in $1 \% \mathrm{HCl}$ solution in ethanol as the spray reagent $\left(R_{\mathrm{f}}=0.905\right)$. Molecular ion peak at $171 \mathrm{amu}$ confirms $p$-toluenesulfonamide. All other peaks observed in GC-MS can be interpreted in accordance with the observed structure. It was also noticed that there was no further oxidation of these products under the present set of experimental conditions. Nitrogen was identified by the conventional test. The oxidation reaction fails to induce the polymerization of added acrylonitrile, indicating the absence of free radicals in the reaction.

The kinetics of oxidation of SY by CAT was investigated at several initial concentrations of the reactants in presence of $\mathrm{HClO}_{4}$ and in $\mathrm{NaOH}$ medium catalyzed by $\mathrm{Os}(\mathrm{VIII})$ at $298 \mathrm{~K}$ and $303 \mathrm{~K}$, respectively. The stoichiometry and oxidation products are same in both the media, but their kinetic characteristics were found to be different. This suggests that the mechanism of oxidation of SY by CAT in acid and alkaline media also to be different. All the kinetic runs were carried out spectrophotometrically at $\lambda_{\max } 483 \mathrm{~nm}$ under pseudo-first-order conditions, wherein $[\mathrm{CAT}]_{0} \gg[\mathrm{SY}]_{0}$.

\subsection{Kinetics of oxidation of SY by $\mathrm{CAT}$ in $\mathrm{HClO}_{4}$ medium}

With the oxidant concentration in excess, at constant [substrate $]_{0},\left[\mathrm{HClO}_{4}\right]$ and temperature, plots of $\log$ (absorbance) versus time were linear $(r>0.9938)$, indicating a first-order dependence of rate on $[S Y]_{0}$. The pseudo-first-order rate constants $\left(k^{\prime} \mathrm{s}^{-1}\right)$ are unaffected with variation of $[S Y]_{0}$, confirming a first-order dependence of rate on [SY $]_{0}$ (Table 1). Values of $k^{\prime}$ increases with increase in [CAT $]_{0}$ (Table 1 ) and a plot of $\log k^{\prime}$ versus log [CAT] was linear $(r=0.9905)$ with a slope of unity, indicating a first-order depen- dence of rate on $[\text { CAT }]_{0}$. Further, a plot of $k^{\prime}$ versus [CAT $]_{0}$ was linear $(r=0.9921)$ passing through the origin, establishing a firstorder dependence on [CAT $]_{0}$ and also the intermediates formed are of transient existence. There was a decrease in rate with an increase in $\left[\mathrm{HClO}_{4}\right]$ (Table 1 ) and a plot of $\log k^{\prime}$ versus $\log \left[\mathrm{HClO}_{4}\right]$ was linear $(r=0.9889)$ with a negative slope of 0.46 , indicating an inverse-fractional-order dependence of rate on $\left[\mathrm{HClO}_{4}\right]$.

Addition of $p$-toluenesulfonamide or $\mathrm{TsNH}_{2}\left(1.0 \times 10^{-3}\right.$ $8.0 \times 10^{-3} \mathrm{~mol} \mathrm{dm}^{-3}$ ) to the reaction mixture did not affect the rate significantly. Similarly, $\mathrm{Cl}^{-}$or $\mathrm{Br}^{-}$ions in the form of $\mathrm{NaCl}$ or $\operatorname{NaBr}\left(4.0 \times 10^{-3}-12.0 \times 10^{-3} \mathrm{~mol} \mathrm{dm}^{-3}\right)$ had no pronounced effect on the rate. The reaction was studied at different temperatures 
Table 1

Effect of varying concentrations of CAT, SY and $\mathrm{HClO}_{4}$ on the reaction rate at $298 \mathrm{~K}$

\begin{tabular}{lllc}
\hline $\begin{array}{l}{[\mathrm{CAT}]_{0} \times 10^{3}} \\
\left(\mathrm{~mol} \mathrm{dm}^{-3}\right)\end{array}$ & $\begin{array}{l}{[\mathrm{SY}]_{0} \times 10^{4}} \\
\left(\mathrm{~mol} \mathrm{dm}^{-3}\right)\end{array}$ & $\begin{array}{l}{\left[\mathrm{HClO}_{4}\right] \times 10^{4}} \\
\left(\mathrm{~mol} \mathrm{dm}^{-3}\right)\end{array}$ & $\begin{array}{c}k^{\prime} \times 10^{4} \\
\left(\mathrm{~s}^{-1}\right)\end{array}$ \\
\hline 0.2 & 1.0 & 1.0 & 1.64 \\
0.5 & 1.0 & 1.0 & 3.59 \\
1.0 & 1.0 & 1.0 & 8.31 \\
2.0 & 1.0 & 1.0 & 14.3 \\
4.0 & 1.0 & 1.0 & 28.5 \\
1.0 & 0.2 & 1.0 & 8.44 \\
1.0 & 0.4 & 1.0 & 8.39 \\
1.0 & 1.0 & 1.0 & 8.31 \\
1.0 & 2.0 & 1.0 & 7.92 \\
1.0 & 4.0 & 1.0 & 8.66 \\
1.0 & 1.0 & 0.2 & 17.3 \\
1.0 & 1.0 & 0.5 & 12.5 \\
1.0 & 1.0 & 1.0 & 8.31 \\
1.0 & 1.0 & 2.0 & 4.26 \\
1.0 & 1.0 & 4.0 & 2.12 \\
\hline
\end{tabular}

Table 2

Temperature dependence and activation parameters for the oxidation of SY by CAT in $\mathrm{HClO}_{4}$ medium and in $\mathrm{NaOH}$ medium with and without $\mathrm{Os}(\mathrm{VIII})$ catalyst $^{\mathrm{a}}$

\begin{tabular}{|c|c|c|c|c|}
\hline \multirow[t]{3}{*}{ Temperature (K) } & \multicolumn{3}{|l|}{$k^{\prime} \times 10^{4}\left(\mathrm{~s}^{-1}\right)$} & \multirow[t]{3}{*}{$K_{\mathrm{C}}$} \\
\hline & \multirow{2}{*}{$\begin{array}{l}\text { Acid } \\
\text { medium }\end{array}$} & \multicolumn{2}{|c|}{ Alkaline medium } & \\
\hline & & $\begin{array}{l}\text { Os(VIII) } \\
\text { catalyzed }\end{array}$ & Uncatalyzed & \\
\hline 288 & 4.41 & & & \\
\hline 293 & 6.24 & 3.67 & 0.38 & 1.34 \\
\hline 298 & 8.31 & 4.82 & 0.52 & 2.93 \\
\hline 303 & 12.0 & 6.39 & 0.95 & 4.81 \\
\hline 308 & 16.0 & 9.17 & 1.91 & 11.2 \\
\hline 313 & & 13.7 & 2.52 & 19.8 \\
\hline$E_{\mathrm{a}}\left(\mathrm{kJ} \mathrm{mol} \mathrm{mo}^{-1}\right)$ & 43.5 & 50.3 & 80.5 & 100 \\
\hline$\Delta H^{\neq}\left(\mathrm{kJ} \mathrm{mol}^{-1}\right)$ & $41.0 \pm 0.01$ & $47.8 \pm 0.01$ & $78.0 \pm 0.13$ & $97.5 \pm 0.01$ \\
\hline$\Delta S^{f}\left(\mathrm{~J} \mathrm{~K}^{-1} \mathrm{~mol}^{-1}\right)$ & $-165 \pm 0.20$ & $-147 \pm 0.11$ & $-63.5 \pm 0.23$ & $-90.0 \pm 0.13$ \\
\hline$\Delta G^{\neq}\left(\mathrm{kJ} \mathrm{mol}{ }^{-1}\right)$ & $90.3 \pm 0.13$ & $92.5 \pm 0.25$ & $98.3 \pm 0.14$ & $124 \pm 0.12$ \\
\hline $\log A$ & $4.55 \pm 0.15$ & $7.78 \pm 0.09$ & $9.95 \pm 0.21$ & $8.84 \pm 0.02$ \\
\hline
\end{tabular}

Also values of catalytic constant $\left(K_{\mathrm{C}}\right)$ at different temperature and activation parameters calculated using $K_{\mathrm{C}}$ values.

${ }^{\mathrm{a}}[\mathrm{CAT}]_{0}=1.0 \times 10^{-3} \mathrm{~mol} \mathrm{dm}^{-3} ; \quad[\mathrm{SY}]_{0}=1.0 \times 10^{-4} \mathrm{~mol} \mathrm{dm}^{-3} ; \quad\left[\mathrm{HClO}_{4}\right]=1.0 \times$ $10^{-4} \mathrm{~mol} \mathrm{dm}^{-3} ;[\mathrm{NaOH}]=1.0 \times 10^{-3} \mathrm{~mol} \mathrm{dm}^{-3} ;[\mathrm{Os}(\mathrm{VIII})]=2.0 \times 10^{-5} \mathrm{~mol} \mathrm{dm}^{-3}$.

(288-308 K) and from the linear plot of $\log k^{\prime}$ versus $1 / T$ $(r=0.9923)$, the values of activation parameters $\left(E_{\mathrm{a}}, \Delta H^{\neq}, \Delta S^{\neq}\right.$, $\Delta G^{\neq}$and $\log A$ ) for the overall reaction were computed (Table 2). The solvent isotope effect was studied using $\mathrm{D}_{2} \mathrm{O}$ and the reaction rate was further decreased with $k^{\prime}=6.55 \times 10^{-4} \mathrm{~s}^{-1}$ in $\mathrm{D}_{2} \mathrm{O}$ medium and $8.31 \times 10^{-4} \mathrm{~s}^{-1}$ in $\mathrm{H}_{2} \mathrm{O}$, leading to a solvent isoptope effect of $k^{\prime}\left(\mathrm{H}_{2} \mathrm{O}\right) / \mathrm{k}^{\prime}\left(\mathrm{D}_{2} \mathrm{O}\right)=1.27$.

\subsection{Kinetics of oxidation of SY by CAT in $\mathrm{NaOH}$ medium}

The reactant concentrations were varied under pseudo-first-order conditions: $[\mathrm{CAT}]_{0} \gg[\mathrm{SY}]_{0}$ at constant $[\mathrm{NaOH}],[\mathrm{Os}(\mathrm{VIII})]$ and temperature. Plots of $\log [S Y]_{0}$ versus time were linear $(r>$ $0.9986)$, indicating a first-order dependence of rate on $[S Y]_{0}$. The values of $k^{\prime}$ were unaffected by the variation of $[\mathrm{SY}]_{0}$, confirming the first-order dependence of rate on $[S Y]_{0}$ (Table 3 ). The rate increases with increase in [CAT $]_{0}$ (Table 3 ) and a first-order dependence on $[\mathrm{CAT}]_{0}$ is noted, as the plot of $\log k^{\prime}$ versus $\log [\mathrm{CAT}]_{0}$ is linear ( $r=0.9899$ ) with a unit slope. Further, a plot of $k^{\prime}$ versus $[C A T]_{0}$ was linear $(r=0.9951)$ passed through the origin, confirming
Table 3

Effect of varying concentrations of CAT, SY, $\mathrm{NaOH}$ and $\mathrm{Os}(\mathrm{VIII})$ on the reaction rate at $303 \mathrm{~K}$

\begin{tabular}{llllc}
\hline $\begin{array}{l}{[\mathrm{CAT}]_{0} \times 10^{3}} \\
\left(\mathrm{~mol} \mathrm{dm}^{-3}\right)\end{array}$ & $\begin{array}{l}{[\mathrm{SY}]_{0} \times 10^{4}} \\
\left(\mathrm{~mol} \mathrm{dm}^{-3}\right)\end{array}$ & $\begin{array}{l}{[\mathrm{Os}(\mathrm{VIII})] \times 10^{5}} \\
\left(\mathrm{~mol} \mathrm{dm}^{-3}\right)\end{array}$ & $\begin{array}{l}{[\mathrm{NaOH}] \times 10^{3}} \\
\left(\mathrm{~mol} \mathrm{dm}^{-3}\right)\end{array}$ & $\begin{array}{c}k^{\prime} \times 10^{4} \\
\left(\mathrm{~s}^{-1}\right)\end{array}$ \\
\hline 0.2 & 1.0 & 2.0 & 1.0 & 1.51 \\
0.5 & 1.0 & 2.0 & 1.0 & 3.39 \\
1.0 & 1.0 & 2.0 & 1.0 & 6.39 \\
2.0 & 1.0 & 2.0 & 1.0 & 13.1 \\
4.0 & 1.0 & 2.0 & 1.0 & 25.0 \\
1.0 & 0.2 & 2.0 & 1.0 & 6.55 \\
1.0 & 0.4 & 2.0 & 1.0 & 6.37 \\
1.0 & 1.0 & 2.0 & 1.0 & 6.39 \\
1.0 & 2.0 & 2.0 & 1.0 & 6.58 \\
1.0 & 4.0 & 2.0 & 1.0 & 6.67 \\
1.0 & 1.0 & 0.5 & 1.0 & 1.90 \\
1.0 & 1.0 & 1.0 & 1.0 & 3.83 \\
1.0 & 1.0 & 2.0 & 1.0 & 6.39 \\
1.0 & 1.0 & 5.0 & 1.0 & 14.6 \\
1.0 & 1.0 & 10.0 & 1.0 & 24.9 \\
1.0 & 1.0 & 2.0 & 0.1 & 3.83 \\
1.0 & 1.0 & 2.0 & 0.5 & 5.17 \\
1.0 & 1.0 & 2.0 & 1.0 & 6.39 \\
1.0 & 1.0 & 2.0 & 2.0 & 7.67 \\
1.0 & 1.0 & 2.0 & 5.0 & 9.17 \\
\hline
\end{tabular}

the first-order dependence on [CAT $]_{0}$ and the intermediates formed are of transient existence. The rate increased with increase in [NaOH] (Table 3 ) and a plot of $\log k^{\prime}$ versus $\log [\mathrm{NaOH}]$ was linear $(r=0.9899)$ with a slope of 0.23 , indicating the fractional-order dependence of rate on $[\mathrm{NaOH}]$. Similarly, the reaction rate increased with increase in [Os(VIII)] (Table 3) and the plot of $\log k^{\prime}$ versus log $[\mathrm{Os}(\mathrm{VIII})]$ gave a straight line $(r=0.9972)$ with a slope less than unity (0.84), indicating a fractional-order dependence on [Os(VIII)].

Addition of $p$-toluenesulfonamide $\left(1.0 \times 10^{-3}-8.0 \times 10^{-3}\right.$ $\left.\mathrm{mol} \mathrm{dm}{ }^{-3}\right)$ and $\mathrm{NaCl}$ or $\mathrm{NaBr}\left(4.0 \times 10^{-3}-12.0 \times 10^{-3} \mathrm{~mol} \mathrm{dm}^{-3}\right)$ had no significant effect on the rate. The reaction rate was further increased in $\mathrm{D}_{2} \mathrm{O}$ with $k^{\prime}=8.74 \times 10^{-4} \mathrm{~s}^{-1}$ and $6.39 \times 10^{-4} \mathrm{~s}^{-1}$ in $\mathrm{H}_{2} \mathrm{O}$ leading to a solvent isotope effect, $k^{\prime}\left(\mathrm{H}_{2} \mathrm{O}\right) / \mathrm{k}^{\prime}\left(\mathrm{D}_{2} \mathrm{O}\right)=0.73$. The reaction was found to obey Arrhenius temperature dependence (293-313 K) and from the linear plot of $\log k^{\prime}$ versus $1 / T(r=0.9899)$, activation parameters were evaluated (Table 2 ).

\subsection{Reactive species of CAT and SY}

Chloramine-T acts as an oxidizing agent in both acidic and alkaline media [17-22]. The redox potential of chloramine-T/sulfonamide system [23] is $\mathrm{pH}$ dependent $(1.139,0.778$ and $0.614 \mathrm{~V}$ at $\mathrm{pH} 0.65,7.0$ and 9.7, respectively) and decreasing with increase in $\mathrm{pH}$ of the medium. The existence of similar equilibria in acid and alkaline solutions of CAT has been reported by Morris et. al. [17], Ruff and Kucsman [18], Bishop and Jennings [19], Hardy and Johnston [20], Pryde and Soper [21] and Higuchi et al. [22]. Aqueous solution of chloramine-T (TsNClNa) behaves as a strong electrolyte [19] and depending on the $\mathrm{pH}$, it furnishes different types of reactive species. The possible oxidizing species in acidified CAT solutions are the conjugate free acid ( $\mathrm{TsNHCl}$ ), dichloramine-T $\left(\mathrm{TsNCl}_{2}\right)$, hypochlorous acid $(\mathrm{HOCl})$ and possibly $\mathrm{H}_{2} \mathrm{OCl}^{+}$, and in alkaline solutions $\mathrm{TsNHCl}, \mathrm{HOCl}, \mathrm{TsNCl}^{-}$and $\mathrm{OCl}^{-}$.

Dyes, such as sunset yellow, containing hydroxy groups conjugated to azo group exhibit azo-hydrazone tautomerism as shown below. For dyes where the hydroxyl group is ortho to the azo link, the aqueous solution favors hydrazone form [24]. In the present case, hydrazone form of sunset yellow is involved in the reaction. 




(Azo form)<smiles>O=C1C=Cc2cc(S(=O)(=O)O)ccc2/C1=N/Nc1ccc(S(=O)(=O)O)cc1</smiles>

Since rate $=k^{\prime}[\mathrm{CAT}]_{t}$, Eq. (5) can be transformed as,

\subsection{Reaction mechanism and rate law in acid medium}

The probable oxidizing species in acidified CAT solutions are TsNHCl, TsNCl $2, \mathrm{HOCl}$ and $\mathrm{H}_{2} \mathrm{OCl}^{+}$. If $\mathrm{TsNCl}_{2}$ and $\mathrm{HOCl}$ were to behave as reactive species, then the rate law would have followed a second-order dependence on [CAT $]_{0}$ and a first-order retardation by the added $\left[\mathrm{TsNH}_{2}\right]$. However, experimental observations are quite contrary to these expectations. Similarly, if $\mathrm{H}_{2} \mathrm{OCl}^{+}$were to be the reactive species, there would have been a positive effect of $\left[\mathrm{H}^{+}\right]$on the rate, which did not occur. Therefore TsNHCl can be assumed as the reactive oxidizing species for the oxidation of SY by CAT in acid medium.

Formation of species of the type $\mathrm{TsNH}_{2} \mathrm{Cl}^{+}$has been reported [25-26] with CAT and the protonation constant for the reaction,

$$
\mathrm{TsNHCl}+\mathrm{H}^{+} \rightleftharpoons \mathrm{TsNH}_{2} \mathrm{Cl}^{+}
$$

is found to be $1.02 \times 10^{2}$ at $298 \mathrm{~K}$. In the present case, an inversefractional-order in $\left[\mathrm{H}^{+}\right]$suggests that the deprotonation of $\mathrm{TsNH}_{2} \mathrm{Cl}^{+}$ results in the regeneration of $\mathrm{TsNHCl}$, which is the most likely active oxidant species involved in the mechanism of SY oxidation. In view of these facts, a general mechanism (Scheme 1) was proposed to substantiate the observed kinetics during the oxidation of SY by CAT in acid medium.

The structure of the complex intermediate species $(\mathrm{X})$ is shown in Scheme 2, where a detailed mechanistic picture of CAT-SY reaction in acid medium is illustrated. is

According to Scheme 1, the total effective concentration of CAT

$$
[\mathrm{CAT}]_{t}=\left[\mathrm{TsNH}_{2} \mathrm{Cl}^{+}\right]+[\mathrm{TsNHCl}]
$$

From step (i) of Scheme 1, one can obtain the value of [TsNHCl] as

$$
[\mathrm{TsNHCl}]=\frac{K_{1}[\mathrm{CAT}]_{t}}{K_{1}+\left[\mathrm{H}^{+}\right]}
$$

From the slow step (ii) of Scheme 1,

$$
\text { rate }=k_{2}[\mathrm{TsNHCl}][\mathrm{SY}]
$$

Upon substituting for [TsNHCl], Eq. (4) yields the following rate law,

$$
\text { rate }=\frac{K_{1} \mathrm{k}_{2}[\mathrm{CAT}]_{t}[\mathrm{SY}]}{K_{1}+\left[\mathrm{H}^{+}\right]}
$$

Rate law (5) is in accordance with the observed experimental results.

$$
\begin{array}{ll}
\mathrm{TsNH}_{2} \mathrm{Cl}^{+} \stackrel{\mathrm{K}_{1}}{=} \mathrm{TsNHCl}+\mathrm{H}^{+} & \text {(i) fast } \\
\mathrm{TsNHCl}+\mathrm{SY} \stackrel{\mathrm{k}_{2}}{\longrightarrow} \mathrm{X}+\mathrm{TsNH}_{2} & \text { (ii) slow and rate determining } \\
\mathrm{X}+\mathrm{H}_{2} \mathrm{O} \stackrel{\mathrm{k}_{3}}{\longrightarrow} \text { Products } & \text { (iii) fast }
\end{array}
$$

Scheme 1. A general scheme for the oxidation of SY by CAT in acid medium.

$\frac{1}{k^{\prime}}=\frac{1}{k_{2}[\mathrm{SY}]}+\frac{\left[\mathrm{H}^{+}\right]}{K_{1} k_{2}[\mathrm{SY}]}$

From the linear double reciprocal plot of $1 / \mathrm{k}^{\prime}$ versus $\left[\mathrm{H}^{+}\right]$ $(r=0.9930)$, values of deprotonation constant $K_{1}$ and decomposition constant $k_{2}$ could be calculated and are found to be $5.38 \times 10^{3} \mathrm{~mol} \mathrm{dm}^{-3}$ and $9.29 \times 10^{-3} \mathrm{~s}^{-1}$, respectively.

\subsection{Reaction mechanism and rate law in alkaline medium}

In alkaline solutions of CAT, $\mathrm{TsNCl}_{2}$ and $\mathrm{H}_{2} \mathrm{OCl}^{+}$does not exist and the possible species are $\mathrm{TsNHCl}, \mathrm{HOCl}$ and $\mathrm{TsNCl}^{-}$. Hardy and Johnston [20] have also reported the existence of the following equilibria in alkaline solutions of CAT

$$
\begin{aligned}
& \mathrm{TsNCl}^{-}+\mathrm{H}_{2} \mathrm{O} \stackrel{K_{\mathrm{a}}^{\prime}}{\rightleftharpoons} \mathrm{TsNHCl}+\mathrm{OH}^{-} \\
& \mathrm{TsNHCl}+\mathrm{H}_{2} \mathrm{O} \stackrel{K_{\mathrm{h}}^{\prime}}{\rightleftharpoons} \mathrm{TsNH}_{2}+\mathrm{HOCl}
\end{aligned}
$$

$K_{\mathrm{h}}^{\prime}=4.21 \times 10^{-3}$ at $298 \mathrm{~K}$

As Eq. (8) indicates a slow hydrolysis, if $\mathrm{HOCl}$ were the primary oxidizing species, a first-order retardation of the rate by the added p-toluenesulfonamide would be expected. However, no such effect was noticed. In the present investigations, a fractional-order dependence on $\left[\mathrm{OH}^{-}\right]$indicates that the anion species $\mathrm{TsNCl}^{-}$, formed from TsNHCl, is responsible for the oxidation of SY by CAT in alkaline medium.

It has been shown that osmium is stable in its +8 oxidation state [27-29] and in alkaline solutions the following equilibria exist

$\mathrm{O}_{\mathrm{s}} \mathrm{O}_{4}+\mathrm{OH}^{-}+\mathrm{H}_{2} \mathrm{O} \rightleftharpoons\left[\mathrm{O}_{\mathrm{s}} \mathrm{O}_{4}(\mathrm{OH})\left(\mathrm{H}_{2} \mathrm{O}\right)\right]^{-}$

$\left[\mathrm{O}_{\mathrm{s}} \mathrm{O}_{4}(\mathrm{OH})\left(\mathrm{H}_{2} \mathrm{O}\right)\right]^{-}+\mathrm{OH}^{-} \rightleftharpoons\left[\mathrm{O}_{\mathrm{s}} \mathrm{O}_{4}(\mathrm{OH})_{2}\right]^{2-}+\mathrm{H}_{2} \mathrm{O}$

Both $\left[\mathrm{OsO}_{4}(\mathrm{OH})\left(\mathrm{H}_{2} \mathrm{O}\right)\right]^{-}$and $\left[\mathrm{OsO}_{4}(\mathrm{OH})_{2}\right]^{2-}$ posses octahedral geometry and they may not be able to form effective complexes with an oxidant. It is more realistic to postulate that $\mathrm{OsO}_{4}$, which possesses tetrahedral geometry, as the active catalyst species that can effectively form a complex with the oxidant species. Further, the first-order-dependence of the rate on $[\mathrm{CAT}]_{0}$ and $[\mathrm{SY}]_{0}$, a fractional-order dependence each on $\left[\mathrm{OsO}_{4}\right]$ and $\left[\mathrm{OH}^{-}\right]$, indicates that the intermediate complex formed from $\mathrm{OsO}_{4}$ and CAT interacts with the substrate in the slow step.

The existence of a complex between catalyst and oxidant was evidenced from the UV-Visible spectra of Os(VIII) and Os(VIII)CAT mixture, in which a shift of Os(VIII) from 320 to $314 \mathrm{~nm}$ was observed (Fig. 1), indicating the formation of a complex between Os(VIII)-CAT. Such type of complex formation has also been observed elsewhere [30-31].

Further, for a general equilibrium (11)

$\mathrm{M}+n \mathrm{OX} \stackrel{K}{\rightleftharpoons}\left(\mathrm{MOX}_{n}\right)$

between two metal species $\mathrm{M}$ and $\left(\mathrm{MOX}_{n}\right)$ having different extinction coefficients, Ardon [32] has derived the following Eq. (12) 

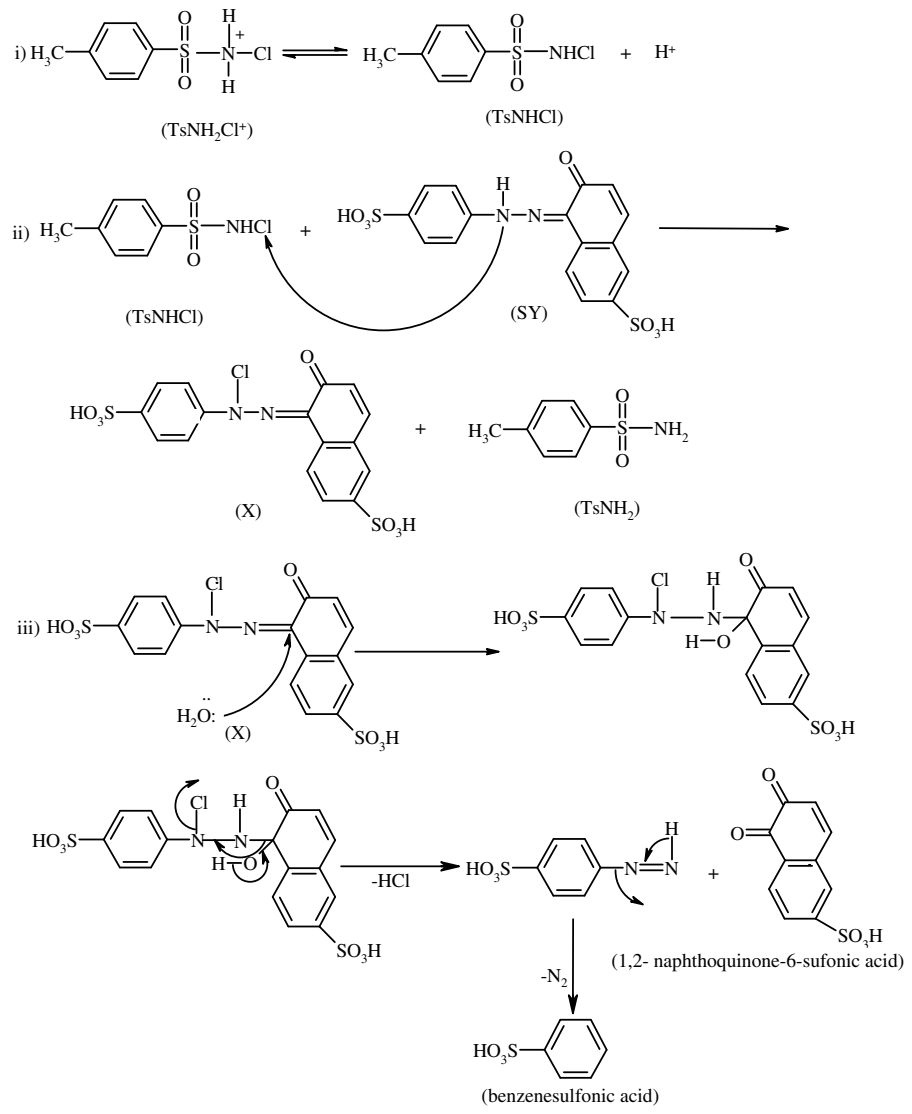

Scheme 2. A detailed mechanistic interpretation for the oxidation of SY by CAT in acid medium.

$1 / \Delta \mathrm{A}=1 /[\mathrm{OX}]^{n}\left\{1 / \Delta \mathrm{E}\left[\mathrm{M}_{\text {total }}\right] K\right\}+1 / \Delta \mathrm{E}\left[\mathrm{M}_{\text {total }}\right]$

where $K$ is the formation constant of the complex, OX is the oxidant, $\Delta E$ is the difference in extinction coefficient between two metal species, $\left[\mathrm{M}_{\text {total }}\right]$ the total concentration of metal species and $\Delta A$ is the absorbance difference of solution in absence of OX and one that contains a certain concentration of OX represented by [OX]. Eq. (12) is valid provided that $[\mathrm{OX}]$ is so much greater than $\left[\mathrm{M}_{\text {total }}\right]$ that the amount of OX bound in the complex is negligible or it is subtracted from the initial concentration of OX. According to Eq. (12), a plot of $1 / \Delta A$ versus $1 /[\mathrm{OX}]$ or $1 /[\mathrm{OX}]^{2}$ should be linear with an intercept in case of $1: 1$ or $1: 2$ type of complex formation between $\mathrm{M}$ and $\mathrm{OX}$. The ratio of intercept to slope of this linear plot gives the value of $K$.

Chloramine- $\mathrm{T}$ in $\mathrm{NaOH}$ medium containing Os(VIII) showed an absorption peak at $314 \mathrm{~nm}$ ( $\lambda_{\max }$ of the complex) and the complex formation studies were made at this $\lambda_{\max }$. In a set of experiments, the solutions were prepared by taking different amounts of CAT

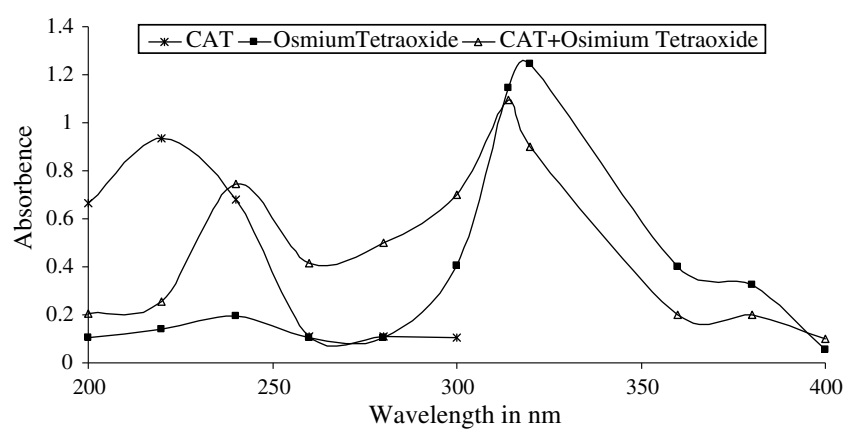

Fig. 1. UV-Visible spectra of CAT, Os(VIII) and CAT-Os(VIII) complex. $\left(0.5 \times 10^{-3}-4.0 \times 10^{-3} \mathrm{~mol} \mathrm{dm}^{-3}\right)$ at constant amounts of Os(VIII) $\left(2.0 \times 10^{-5} \mathrm{~mol} \mathrm{dm}^{-3}\right)$ and $\mathrm{NaOH}\left(1.0 \times 10^{-3} \mathrm{~mol} \mathrm{dm}^{-3}\right)$ at $303 \mathrm{~K}$ The absorbance of these solutions were measured at $314 \mathrm{~nm}$. The absorbance of the solution in the absence of CAT was also measured at the same wavelength. The difference of these absorbance values (with and without CAT) gives the differential absorbance, $\Delta A$. A plot of $1 / \Delta A$ versus $1 /[C A T]$ was linear $(r=0.9955)$ with an intercept suggesting the formation of $1: 1$ complex between CAT and catalyst. From the slope and intercept of the plot $1 / \Delta A$ versus $1 /[\mathrm{CAT}]$, the formation constant, $K$, of the complex was evaluated and was found to be $1.23 \times 10^{3}$.

In the light of these considerations, the mechanism for the Os(VIII) catalyzed oxidation of SY by CAT in $\mathrm{NaOH}$ medium is formulated (Scheme 3). In Scheme 3, $\mathrm{X}^{\prime}$ and $\mathrm{X}^{\prime \prime}$ represent the complex intermediate species whose structures are shown in Scheme 4, where a detailed mechanistic mode of Os(VIII) catalyzed SY oxidation by CAT in alkaline medium is depicted.

The total effective concentration of CAT is

$[\mathrm{CAT}]_{t}=[\mathrm{TsNHCl}]+\left[\mathrm{TsNCl}^{-}\right]+\left[\mathrm{X}^{\prime}\right]$

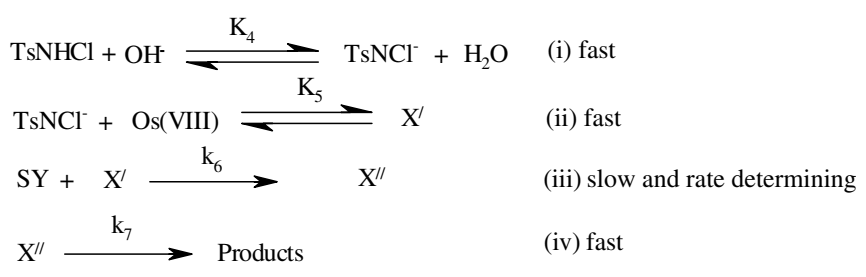

Scheme 3. A general scheme for the Os(VIII) catalyzed oxidation of SY by CAT in alkaline medium. 



$\left(\mathrm{X}^{\prime}\right)$


Scheme 4. A detailed mechanistic interpretation for the Os(VIII) catalyzed oxidation of SY by CAT in alkaline medium. 
From steps (i) and (ii) of Scheme 3, solving for $\left[\mathrm{X}^{\prime}\right]$. One obtains,

$\left[\mathrm{X}^{\prime}\right]=\frac{K_{4} K_{5}[\mathrm{CAT}]_{t}\left[\mathrm{OH}^{-}\right][\mathrm{Os}(\mathrm{VIII})]}{\left[\mathrm{H}_{2} \mathrm{O}\right]+K_{4}\left[\mathrm{OH}^{-}\right]+K_{4} K_{5}\left[\mathrm{OH}^{-}\right][\mathrm{Os}(\mathrm{VIII})]}$

From the slow step (iii) of Scheme 3,

rate $=k_{6}\left[\mathrm{X}^{\prime}\right][\mathrm{SY}]$

By substituting $\left[\mathrm{X}^{\prime}\right]$ from Eq. (14) in Eq. (15), the following rate law (16) is obtained,

rate $=\frac{K_{4} K_{5} k_{6}[\mathrm{CAT}]_{t}[\mathrm{SY}]\left[\mathrm{OH}^{-}\right][\mathrm{Os}(\mathrm{VIII})]}{\left[\mathrm{H}_{2} \mathrm{O}\right]+K_{4}\left[\mathrm{OH}^{-}\right]+K_{4} K_{5}\left[\mathrm{OH}^{-}\right][\mathrm{Os}(\mathrm{VIII})]}$

Rate expression (16) fits well to the experimental data. The proposed reaction mechanisms and the derived rate laws in both the media are also substantiated by the following observed experimental facts:

The observed solvent isotope effects in acid and alkaline media support the proposed mechanisms and the derived rate expressions. For a reaction involving a fast equilibrium $\mathrm{H}^{+}$or $\mathrm{OH}^{-}$ion transfer, the rate increases in $\mathrm{D}_{2} \mathrm{O}$ since $\mathrm{D}_{3} \mathrm{O}^{+}$and $\mathrm{OD}^{-}$are stronger acid and stronger base ( $\sim 2-3$ times greater), respectively, than $\mathrm{H}_{3} \mathrm{O}^{+}$and $\mathrm{OH}^{-}$ions [33-34]. The reverse holds good for reactions involving retardation by $\mathrm{H}^{+}$or $\mathrm{OH}^{-}$ions. In the present investigations, the observed solvent isotope effects of $k^{\prime}\left(\mathrm{H}_{2} \mathrm{O}\right) / k^{\prime}\left(\mathrm{D}_{2} \mathrm{O}\right)>1$ and $k^{\prime}\left(\mathrm{H}_{2} \mathrm{O}\right) / k^{\prime}\left(\mathrm{D}_{2} \mathrm{O}\right)<1$ in acid and alkaline media, respectively, conform to the above theory.

It was felt indispensable to compare the reactivity of SY by CAT in alkaline medium with and without Os(VIII) catalyst under identical experimental conditions (Table 2). The reaction was carried out at different temperatures (293-313 K) without Os(VIII) catalyst and from the linear plot of $\log k^{\prime}$ versus $1 / T(r=0.9956)$, activation parameters for the uncatalyzed reactions were computed (Table 2). It was found that Os(VIII) catalyzed reaction is about seven-fold faster than the uncatalyzed reaction and was also confirmed by the values of activation parameters. Hence, the observed reaction rate in presence of $\mathrm{Os}(\mathrm{VIII})$ catalyst justifies the facile oxidation of SY by CAT in alkaline medium. Consequently, it can be concluded that Os(VIII) is an efficient catalyst for the facile oxidation of SY by CAT in alkaline medium.

Further, it has been pointed out by Moelwyn-Hughes [35] that even in presence of the catalyst, the uncatalyzed and catalyzed reactions proceed simultaneously, so that

$k_{1}=k_{0}+K_{\mathrm{C}}[\text { catalyst }]^{x}$

Here $k_{1}$ and $k_{0}$ are the specific rate constants in presence and absence of Os(VIII) catalyst, respectively, $K_{\mathrm{C}}$ is the catalytic constant and $\mathrm{x}$ is the order of the reaction with respect to $\mathrm{Os}(\mathrm{VIII})$ and is found to be 0.84 in the present study. The value of $K_{\mathrm{C}}$ was calculated at different temperatures using Eq. (18)

$K_{\mathrm{C}}=\left(k_{1}-k_{0}\right) /[\mathrm{Os}(\mathrm{VIII})]^{0.84}$

The values of $K_{\mathrm{C}}$ were found to vary with temperature. A plot of log $K_{\mathrm{C}}$ versus $1 / T$ was linear $(r=0.9935)$ and the values of activation parameters with respect to the catalyst were computed. All these results are summarized in Table 2 .

Furthermore, a plot of rate constant for the catalyzed reaction $k^{\prime}$ versus $[\mathrm{Os}(\mathrm{VIII})]$ at $303 \mathrm{~K}$ (Table 3) was found to be linear $(r=0.9873)$ with an intercept. The ordinate intercept is the rate constant for the uncatalyzed reaction $\left(k_{0}\right)$ through the relationship $k_{0}=$ Intercept $+k^{\prime}[\mathrm{Os}(\mathrm{VIII})]$ and it signifies that both catalyzed and uncatalyzed pathways proceed simultaneously. The value of $k_{\mathrm{o}}$ was found to be $1.04 \times 10^{-4} \mathrm{~s}^{-1}$, which is in good agreement with that obtained in the absence of Os(VIII) catalyst $\left(k_{0}=0.95 \times 10^{-4} \mathrm{~s}^{-1}\right)$ (Table 2) at $303 \mathrm{~K}$. This clearly establishes the above relationship.
The proposed mechanisms are also substantiated by the calculated values of energy of activation and other thermodynamic parameters (Table 2). The fairly high positive values of Gibb's free energy of activation and enthalpy of activation indicate that the transition state is highly solvated, while the negative entropy of activation accounts for the formation of a compact activated complex with a fewer degrees of freedom. Addition of $p$-toluenesulfonamide has no effect on the rate, indicating that it was not involved in pre-equilibrium with the oxidant. The rate was unchanged by the addition of halide ions to the reaction mixture, showing that free chlorine is not involved in the oxidation process. All these observations are also in conformity with the proposed mechanisms in both the media.

\section{Conclusions}

The kinetics of oxidation of SY by CAT have been studied in $\mathrm{HClO}_{4}$ and $\mathrm{NaOH}$ media with $\mathrm{Os}(\mathrm{VIII})$ as a catalyst in the latter medium. In acid medium, the rate being: $-\mathrm{d}[\mathrm{CAT}] / \mathrm{d} t=k[\mathrm{CAT}]_{0}$ $[\mathrm{SY}]_{0}\left[\mathrm{HClO}_{4}\right]^{-0.46}$, which changes to $-\mathrm{d}[\mathrm{CAT}] / \mathrm{d} t=k[\mathrm{CAT}]_{0}[\mathrm{SY}]_{0}$ $[\mathrm{NaOH}]^{0.23}\left[\mathrm{OsO}_{4}\right]^{0.84}$ in presence of alkali. Activation parameters for the overall reaction and also with respect to catalyst have been computed. In alkaline medium, it was found that Os(VIII) catalyzed reaction is about seven-fold faster than the uncatalyzed reaction and hence it can be concluded that Os(VIII) is an efficient catalyst in the facile oxidation of SY by CAT in alkaline medium. Suitable mechanisms and appropriate rate laws have been worked out to account for the observed kinetics.

\section{Acknowledgements}

One of the authors (K.N.V) is grateful to the Bangalore University, Bangalore for awarding the Research Fellowship under Interdisciplinary Collaborative Research Project.

\section{References}

[1] V.J. Jennings, CRC Crit. Rev.. Anal. Chem. (1974) 410.

[2] M.M. Campbell, G. Johnson, Chem. Rev. 78 (1978) 65

[3] M.C. Agarwal, S.K. Upadhyay, J. Sci. Ind. Res. 42 (1983) 508

[4] K.K. Banerji, B. Jayaram, D.S. Mahadevappa, J. Sci. Ind. Res. 46 (1987) 65.

[5] K.S. Rangappa, T.E. Daniel, C.K. Mythily, D.S. Mahadevappa, S.Y. Ambekar, Polyhedron 12 (1993) 1719.

[6] A.C. Hegde, B.T. Gowda, Oxd. Commun. 23 (2000) 546

[7] R.J.D. Saldanha, S. Ananda, B.M. Venkatesha, N.M.M. Gowda, J. Mol. Struct. 606 (2002) 147.

[8] Puttaswamy, R.V. Jagadeesh, Ind. Eng. Chem. Res. 45 (2006) 1563.

[9] Puttaswamy, D.S. Mahadevappa, K.S. Rangappa, Bull. Chem. Soc. Jpn. 62 (1989) 3343.

[10] Puttaswamy, R.V. Jagadeesh, Appl. Catal. A: Gen. 292 (2005) 259.

[11] D.M. Marmion, Hand book of US Colorants for Foods, Drugs and Cosmetics, John Wiley \& Sons, New York, 1979.

[12] A.H. Gemeay, A.M. Habib, M.A. Borhan El-Din, Dyes and Pigments 74 (2007) 458.

[13] J.S. Mayell, Ind. Eng. Chem. 7 (2) (1968) 129.

[14] W.P. Griffith, Q. Rev. Chem. Soc. 19 (1965) 254.

[15] F.A. Cotton, G. Wilkinson, Advanced Inorganic Chemistry, second ed., Wiley Eastern, New Delhi, 1966 (pp. 993, 1007).

[16] W.P. Griffith, The Chemistry of Rare Platinum Metals, Inter science, New York, 1967 (p. 42).

[17] J.C. Morris, J.A. Salazar, M.A. Wineman, J. Am. Chem. Soc. 70 (1948) 2036

[18] F. Ruff, A. Kucsman, J. Chem. Soc., Perkin Trans. II (1975) 509.

[19] E. Bishop, V.J. Jennings, Talanta 1 (1958) 197.

[20] F.F. Hardy, J.P. Johnston, J. Chem. Soc., Perkin Trans. II (1973) 742.

[21] B.G. Pryde, F.G. Soper, J. Chem. Soc. (1962) 5982.

[22] T. Higuchi, K. Ikeda, A. Hussain, J. Chem. Soc. B (1969) 549.

[23] A.R.V. Murthy, B.S. Rao, Proc. Indian Acad. Sci. 35 (1952) 69.

[24] J. Oakes, P. Gratton, J. Chem. Soc., Perkin Trans. II (1998) 1857, and reference therein.

[25] S.S. Narayanan, V.R.S. Rao, Rad. Chem. Acta 32 (1983) 211.

[26] M. Subhashini, N. Subramanian, V.R.S. Rao, Talanta 32 (1985) 1082.

[27] A.M. Mackay, R.A. Mackay, Introduction to Modern Inorganic Chemistry, fourth ed., Prentice-Hall, Englewood Cliffs, NJ, 1989 (p. 259). 
[28] F.A. Cotton, G. Wilkinson, P.L. Gaus, Basic Inorganic Chemistry, third ed., Wiley, New York, 1995 (p. 600).

[29] R.D. Saverbrum, E.B. Sandell, J. Am. Chem. Soc. 75 (1953) 4170.

[30] C.P. Kothari, R.M. Mulla, S.T. Nandibewoor, Oxid. Commun. 28 (3) (2005) 579

[31] S.A. Chimatdar, T. Basavaraj, S.T. Nandibewoor, Inorg. React. Mech. 4 (3-4) (2002) 209.
[32] Michael Ardon, J. Chem. Soc. 67 (1957) 1811.

[33] C.J. Collins, N.S. Bowman, Isotope Effects in Chemical Reactions, Van-Nostrand, New York, 1970 (p. 267).

[34] K.B. Wiberg, Chem. Rev. 55 (1955) 713.

[35] E.A. Moelwyn-Hughes, The Kinetics of Reaction in Solutions, Clarendon, Oxford, 1947. 